\title{
How To Prevent Students
}

Linc. Fisch

Eastern Kentucky University

I was relaxed, comfortable, waiting a few moments more until the anesthesia wore completely off. A bit of casual conversation by the dentist might be appropriate, perhaps even expected, after the crown was seated and cemented.

But, there was a hesitant tone in Alix's voice: "Do you mind, uh, if I ask you a question?"

"Of course not," I said, reaching over my shoulder to hit the button to tilt up the chair a bit. I'd spent enough time around dentists that I was quite at ease with them, and I had come to know my way around their environment. In fact, some of my best friends are dentists, Alix among them.

"I feel sort of funny asking you this, but we've known each other for a long time ..."

True; our friendship went back several years to when Alix was a dental student, and we had kept in close touch after graduation. By now, we were colleague-to-colleague, rather than student-professor or patient-dentist.

“. . . well, you know I've always been tuned in to patient education, and I have a practice that is highly oriented to prevention..."

True, again; Alix was a socially sensitive person and had gone to a progressive dental school; I would have expected nothing else.

“. . . but it doesn't always work-I don't seem to be really 
getting through to some of my patients. They come back for recall, and they're in just as bad a shape as on their previous visit. And a few of them almost seem to resent and resist my efforts."

"I know," I said, "a couple of members of my family may be in that category."

A slight, but knowing smile crossed Alix's face.

"What can I do, how can I get them to cooperate, how can I get them to do what they should do?"

In a moment of minor inspiration, I tilted the chair all the way up, swung my legs to the side, and got up.

"Here," I said, "Sit down."

Alix's eyes questioned me.

"Go ahead, sit in the chair," I insisted.

She did, and swung her legs up. I tilted the chair and adjusted it to the appropriately supine treatment position.

"How does it feel?" I asked.

"My God!" Alix exclaimed, "I never realized! It's . . . well, it's like . . . I feel so helpless, so out of control, so vulnerable!"

"Do you suppose that may have anything to do with your patients' attitudes?"

"Yeah, I never thought of it that way before," she replied. "I'm in charge, and they're subservient. No wonder I have trouble getting them to be responsible for their own health care. How could I do that to them?"

"Let me suggest that you didn't do anything to them. Maybe that's just the natural state of affairs between patient and practitioner. Maybe you should focus on what you haven't done to reduce their depending entirely on you. Your professional knowledge and skill are always going to place some distance between you and your patients; you have to accept that, and it's not all bad, of course. But you might search for alternatives that don't accentuate it and for things that you can do that will help keep it from preventing them from becoming good patients."

Alix nodded agreement, tilted the chair, and got up.

We explored the matter further. Another thing that we concluded was that a dentist can do too much for a patient or promise too much-for example, by implying that anything that goes wrong can be "fixed" by the dentist, literally insuring that the patient stays in the dentist's good hands. There is little 
for the patient to be responsible for; there is little need to care about one's own health. In the name of prevention, the patient has been prevented from becoming a good patient.

Alix and I became so involved in discussing these issues that we ran 'way into her next appointment. She scheduled me for another appointment-wisely, for a double one-so that we could continue our exploration of the subject.

When I returned in two weeks, we examined an additional dimension that might lead patients to avoidance behavior, rather than to approach behavior with regard to dental care: the environment of the dental office. Fortunately, there was no inane television set to deal with, but we decided to replace the canned "elevator music" from the local radio station with good tapes carefully selected from Alix's library of recordings. In general, the patient waiting area passed our inspection. A planter that created a minor barrier in front of the receptionist was moved, and a chair was placed in front of the desk for the convenience of patients. The reading material for patients already included an appropriate amount of health information.

Then we considered how Alix and her assistants had been conducting patient education activities. Frequently, conferences with patients were being held at chairside or at a nearby desk. We decided that whenever possible it would be better to carry out this function completely away from the treatment area, at a table where patient and practitioner could sit side by side. The staff also reaffirmed that good communication would be enhanced by their listening attentively to patients' questions and being especially careful to not respond to them prematurely. We even examined how the attire of the staff might affect relationships with patients. Thus we identified a lot of little adjustments that added up to an improved office climate.

When I left Alix's office that day, I felt pretty good. We had discovered a lot that was likely to ameliorate the problem Alix had brought up. I smiled to myself as I anticipated the customary billing that I would get from Alix's office: charges for dental procedures and a final add-on for "preventive dentistry." I mused that maybe I should send her a bill in return, for "preventive education."

However, as I was driving home, my pseudo-smugness began to leave me. A nagging set of thoughts began to creep 
into my head. Alix's question "How can I get my patients to cooperate?" began to translate into my own question: "How can I get my students to cooperate?" Why did I think that her problem with some patients was any different from my problem with some students? How could I get them to work with me rather than to resist my efforts? How could I get them to be responsible rather than to be dependent on me? How could I get them to approach learning rather than to avoid it? Could it be that the things Alix and I had worked out for her practice also needed to be applied in my classroom? Could it be that things I was doing for students, with all good intentions, were actually working against them?

Had I inadvertently been preventing students-independent, responsible students who exercised initiative for their own learning-just as Alix inadvertently had been preventing patients, ironically in the name of prevention itself? It was a sobering thought, and I began to look at my teaching from a new perspective.

Over the years it had become my custom to provide students with a lot of duplicated material: course descriptions, periodic assignment sheets, chapter outlines, sample exams, solution sheets for examinations, and the like. I re-examined these procedures. Some of the material was distributed in the interests of accuracy and efficiency. On the other hand, when it got down to sample exams, I wondered whether I was doing too much for students. Would they not learn more if they had to review the chapters themselves, infer the relative importance of topics, and organize their own study strategies? Wouldn't it be better in the long run if they took this responsibility themselves rather than being dependent on me? Definitely yes, I concluded.

Just before the next examination, I started to work with my students, helping them to organize their review process. By the end of the term I wanted them to be able to do this completely on their own, with my role being reduced to that of a consultant. In another course, I asked the students themselves to design and submit questions that they thought were appropriate for the exam; I used these as the basis for a review during the last class meeting before the test. What were the results? I couldn't tell in any scientific way, of course, but I knew I had made the right moves. (Several students confirmed this on 
the course evaluations.)

For a certain chapter in statistics that contained an unusual mass of intricate formulas, I had been giving out "formula sheets" that students could use during examinations. I changed that process to one of allowing students to bring to the exam one note card, 3 inches by 5 inches, containing on one side whatever information they wished. I cautioned them that putting too much information and full problem solutions on the card could be counterproductive; they might not be able to find what they wanted among all the fine printing. Again, this new procedure seemed to work. Students reported that the very process of organizing and preparing the card helped them learn the material. Some used only part of the card. Many reported that they used the card during the exam only as a final confirmation of information that they had internalized in preparing the card; it was a check, rather than a crutch.

When students asked me to work a troublesome homework problem in class, I used to jump right into it and efficiently produce an ideal solution. Now, I have other students work the problem or at least make significant contributions to the solution. Sometimes they may start to lead me down an unproductive path, but I draw learning out of that, too. The process often takes longer, but I feel the results are well worth it, and I have adjusted my organization and design of class activity to accommodate it.

Flushed with these successes, I continued to look for ways to wean students from depending on me, and one of my main goals has become to try to convert them to responsible, independent learners. One aspect of this is to examine whether I am accenting my authority position too much. To be sure, I am the authority, both in knowledge and in controlling the chips: grades. It would be foolhardy to think that I could mask that fact and the students' perception of it; even if I could, it would probably be undesirable to do so. But I might be able to remove some of the visible symbols of that authority in order to generate more of a climate of working together. In my office, I moved my desk so that it no longer separates me from the student; we work together off the end of the desk. Then, I found an even better arrangement: I moved a conference table so that I can easily shift into working side by side whenever a student comes in for help. 
In the classroom, I don't change from a standing position to a sitting position, given the constant need for board work in my field. However, I have made one change that seems of major significance: I moved the table and lectern from frontand-center to the side of the room. This immediately changed the ambience in the room. Surprisingly, it gave me greater freedom of movement-I no longer had a home base to gravitate back to. I found that taking a position near the ends of the front row seemed to encourage students to participate more in analyzing problems, proposing solutions, and contributing in general to the development of the material. I found that I had to move the table each day before class, because the custodial staff always returned it to the "spot of authority." I didn't mind the small extra effort; now $I$ was defining the climate of the classroom, rather than by default allowing the janitor to do so.

Did my modified classroom behavior work? I think so, although I can offer no data from a controlled experiment to support that contention. I think the response of students was positive, too, as evidenced by comments such as this, made by a student introducing me to his mother: " . . he's a professor, but he's . . . well . . . he's different! He's always working with us."

There were other ways that I tried to adjust the climate of my courses. Taking a cue from Alix, I modified my student conference procedures. Formerly, I had announced "open" conference hours, times when I would definitely be in my office and available for consultation. I knew that students sometimes came by, saw that I was with another student or on the telephone, and then left before I could signal them to wait. Under the new arrangement, I still had definite hours, but I encouraged them to telephone or to see me after class to make an appointment during these times (or at other times, if necessary) in order to not have to wait to see me. The number of conferences increased.

I also tried to arrive early for class and to engage students in informal conversation. I made a point of not doing this from a position in the front of the room; rather, I sat in a seat on the side and varied that position from day to day. I was especially attentive about listening carefully to students.

Well, you get the idea without my citing examples endlessly. 
By keeping in mind two or three basic principles, I continue to find ways of modifying my approach to students so as to promote their skills in learning. (You notice that I do not now list those principles, as you expected; I want you to look back over what I've said and formulate them for yourself.) I'm trying to be particularly sensitive to things that I might be doing in the guise of helping students that in fact might be preventing them, however subtly, from being students. I'm trying to give them the freedom to learn and grow on their own. It's an exciting endeavor.

Today, I got a bill from Alix's office. The last item on it was the charge that I had come to expect, but this time it was worded "patient education." I wrote out a check immediately and on impulse wrote "tuition" in the space on the lower left. Across the bottom of the statement I wrote "THANKS!" in large letters. And added, "-for helping me learn how to teach students rather than to prevent them." I can't wait 'til my next appointment to tell her all about it! 